\title{
Trace Elements in Inclusion-free Diamonds from Venezuela and Arkhangelsk Deposits
}

\author{
Shiryaev, A.A. ${ }^{1}$, Galimov, E.M. ${ }^{1}$, Sobolev, N.V. ${ }^{2}$, Kolesov, G.M. ${ }^{1}$, Zakharchenko, O.D. ${ }^{3}$ \\ 1. V.I.Vernadsky Institute of Geochemistry and Analytical Chemistry RAS, Kosygin St. 19, 117975, Moscow, Russia \\ 2. UIGGM RAS, 630090, Novosibirsk, Russia \\ 3. TsNIGRI, Varshavskoe Sh. 129 B, 113545, Moscow, Russia
}

Substantial role of fluids in processes of diamonds formation was first emphasized by Zezin et al. (1981) and Galimov (1984) from the INAA study of diamonds from Russian deposits. Importance of fluids for diamond origin is confirmed in the present study. In this report we present results of the instrumental neutron activation analyses (INAA) of individual diamond crystals from Venezuela placers and from several pipes of the Arkhangelsk region (NE Europe). Samples from Arkhangelsk region are presented by chips left after inclusions recovery and represent both parageneseses. The data on the composition of mineral inclusions is published elsewhere (Zakharchenko et al., 1991) The parageneses of the Venezuelan diamonds is unknown, however, the absolute predominance of basic inclusions (more than $98 \%$, N.V. Sobolev et al., 1997, submitted) in diamonds from these placers permits to attribute these samples to E-type.

All samples were examined under optical microscope with crossed and parallel polarizers. The magnification used was 50x-500x. No inclusions were detected in analyzed samples under these conditions. The samples were individually boiled in Teflon beakers in mixture of pure acids $\left(\mathrm{HF}+\mathrm{HNO}_{3}\right)$ and rinsed in distilled water before and after irradiation. Integral flux was about $8 \times 10^{17}$ neutrons. KH1 and RUS1 were used as standards and as flux monitors. Samples were counted with a HpGe detector in three periods. The concentration of the following elements were determined by INAA: La, Ce, Sm, Eu, Tb, Yb, Lu, Ca, Sr, Ba, K, Sc, Cr, Fe, Co, Ni, Rb, Na, As, Hf, Zr, Th, U, Ta, $\mathrm{Se}, \mathrm{Zn}, \mathrm{Au}, \mathrm{W}$. Low concentration of impurities and small mass of the samples lead to relatively high errors (up to 50 rel\% at $3 \sigma$ ) for some elements; for majority the errors were less than 20 rel\%. In order to detect surface contamination (if any) by samples preparation, we analyzed (111) surfaces of several diamonds prior and after cleaning procedure by the Rutherford Backscattering (Shiryaev and Kulikauskas, in prep.). It was shown that our treatment introduced small amount of Au. As it is impossible to correct rigorously the INAA figures for gold (1-10 ppb), Au is not discussed further. Trace elements determined in diamonds may be attributed to structural impurities or to microinclusions. As is known, $\mathrm{N}, \mathrm{H}, \mathrm{Ni}$ and $\mathrm{B}$ could present as substitutional or interstitial atoms in natural and synthetic stones. Arsenic and phosphorus could be incorporated as substitutional atoms during HPHT synthesis. The presence of structural oxygen, sulfur in natural Ib diamonds and $\mathrm{Co}$ in synthetic stones was inferred from EPR and luminescence data but these interpretations are not decisive. From results of nuclear probing, IR studies and crushing of diamonds it was suggested (Melton and Giardini, 1981; Navon et al., 1988; Properties of diamond, 1992; Bulanova et al., 1993) that all diamonds contain homogeneously distributed submicroscopic inclusions of a parental magma, consisting of a silicate melt with a miscible carbonate and immiscible sulfide fractions together with volatiles $\left(\mathrm{H}_{2} \mathrm{O}, \mathrm{CO}_{2}, \mathrm{CO}, \mathrm{CH}_{4}\right)$. It is shown that if diamond contains mineral inclusion the output of gases will be higher. The volatiles not related to mineral inclusions may reside in micro cavities. The results of positron annihilation (PAS) studies by Fujii et al..(1995) and our PAS and Small-Angle X-ray Scattering (Shiryaev et al., in prep.) investigations of diamonds of different types in Robertson's classification, clearly point to the existence of voids with sizes ranging approximately from 10 to $25 \mathrm{~A}$ and filled with a low-electron density material. From PAS it follows that pressure in this inclusions exceeds $1 \mathrm{GPa}$. These inclusions could serve as a host for entrapped fluids. 


\section{Results}

The Figures 1 and 2 show the Primitive Mantle-normalized (McDonough and Sun, 1995) element abundances of the diamonds from Venezuela and from Arkhangelsk region, correspondingly. Both suites of diamonds have similar elemental patterns, differences are mostly in the degree of enrichment/depletion. Micro-inclusions in studied diamonds are enriched in LIL and, to lesser extent, by HFSE (Zr). It is unlikely that LILE in our samples are related directly to kimberlite event because $\mathrm{La} / \mathrm{Th}, \mathrm{U} / \mathrm{Th}, \mathrm{K} / \mathrm{Rb}, \mathrm{Sr} / \mathrm{Ba}$ and other ratios does not correspond to kimberlitic or lamproitic values. The presence of fluids (hydrous and/or carbonatitic) could explain the LIL and HFSE enrichment. However, $\mathrm{Zr}$ is believed to be immobile in aqueous fluids and no decisive explanation of its high concentration was made. Apparent significant fractionation of $\mathrm{Zr}$ and $\mathrm{Hf}$ is likely to be explained by experimental artifact. The reason of dramatic depletion in Sm relative to other REE (see also Fig. \#6 in Fesq et al., 1975) is yet unknown: experimental errors for REE are small and this fact has to be explained. Enrichment in $\mathrm{Se}, \mathrm{Sb}$, As points to omnipresent Fe-Ni-Co sulfides.

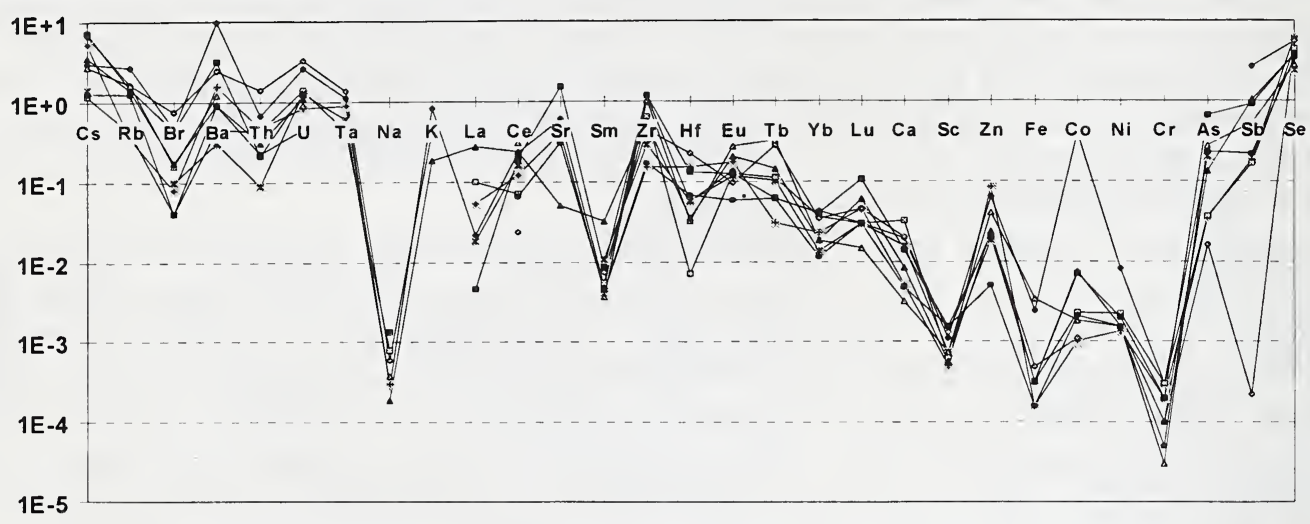

Figure 1. Primitive mantle-normalized element abundances in diamonds from Venezuela

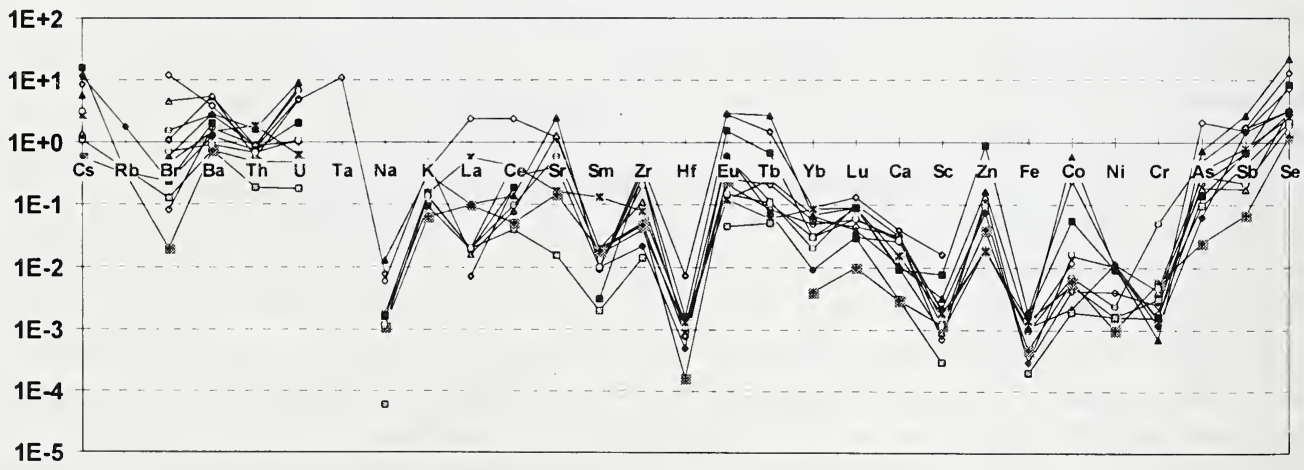

Figure 2. Primitive mantle-normalized element abundances in diamonds from Arkhangelsk region

Some Arkhangelsk diamonds contain micro inclusions which were not detected under a microscope. Intercorrelation of $\mathrm{La}, \mathrm{Ce}, \mathrm{Ba}, \mathrm{Rb}, \mathrm{Cs}$ may infer the presence of carbonates; the detailed analyses have yet to be done. As shown by Shrauder et al. (1996), fibrous diamonds with carbonate-rich fluids have higher concentration of trace elements in comparison with hydrous fluids. Arkhangelsk diamonds have higher level of impurities. We suggest that the fluid participating in formation of Venezuela diamonds was closer to hydrous end-member than that in Arkhangelsk. The more oxidized character of fluids from Arkhangelsk region may be supported by average $\mathrm{Th} / \mathrm{U}$ ratio, which is higher for Venezuelan diamonds. There are some indications that $\mathrm{Th}$ is less mobile in 
oxidized fluid than U. K-enrichment of fluid inclusions in diamonds was already reported (Navon et al., 1988), this fact reveals links of alkaline magmas to the medium of diamonds' formation. Kenrichment could also be explained as involvement of hydrous metasomatic fluid.

\section{Conclusions}

Our and precedent studies reveal a tight relationship of diamonds' crystallization with fluid, enriched in incompatible elements. The fluid could have affinity to deep-seated magmas, such as kimberlites, lamproites, carbonatites. The fluid could be hydrous and/or carbonatitic and should carry sulfides. HPHT synthesis of diamonds from carbon-water system (Yamaoka et al., 1992) and from carbonate melt (Litvin et al., 1997) may be regarded as extreme cases. From morphological studies Sunagawa et al. (1982) were able to conclude that at least octahedral diamonds grew from a solution phase. The fluid $\left(\mathrm{CO}_{2}\right.$-bearing in many cases) induces melting of silicates or mixes with silicate melt, if it was already present. The absence of macroscopic fluid inclusions in diamonds could be explained either by their decripitation during a kimberlite event, by presence of filmy fluids or by complete miscibility of melt-fluid system. In most cases the viscosity of diamonds' growth medium should be low, otherwise diamonds should frequently exhibit plastic deformation, localized in internal parts only, or cellular structure of growth layers (melt growth). These features are sometimes observed in birefringence or in X-ray topographs but are relatively rare. The fluids may originate from several sources: subducted slabs, dehydration of silicates, chemical reactions in C-H-O-S-N system.

\section{References}

Bulanova, G.P., Barashkov, Yu.P., Tal'nikova, S.B., and Smelova, G.B., 1993, Natural Diamond Genetic Aspects. Nauka, Novosibirsk, 176 pp.

Galimov, E.M., 1984, Variations of isotopic composition of diamonds and their relation to conditions of diamonds formation: 8, p. 1091-1118.

Fesq, H.W., Bibby, D.M., Erasmus, C.S., Kable, E.J.D., Sellschop, J.P.F., 1975, A comparative trace element study of diamonds from Premier, Finsch and Jagersfontein mines, South Africa: Phys. Chem. Earth, 9, p. 817-836.

Fujii, S., Nishibayashi, Y., Shikata, S., Uedono, A., Tanigawa, S.,, 1995, Study of various types of diamonds by measurements of double crystal x-ray diffraction and positron annihilation: J. Appl. Phys., 78, p. 1510-1523.

Litvin, Yu.A., Chudinovskih, L.T., Zharikov, V.A., 1997, Crystallization of diamond and graphite in mantle alkali-carbonate melts in experiment at 7-11 GPa: Doklady Acad. Sci., 355, p. 669-672. McDonough, W.F., Sun, S.-S., 1995, The composition of the Earth: Chem. Geol., 120, p. 223-253. Melton, C.E., and Giardini, A.A., 1981, The nature and significance of occluded fluids in three Indian diamonds: Amer. Miner., 66, p. 746-750.

Properties of Diamond, 1992, Ed. Field, J.E., Academic Press.

Navon, O., Hutcheon, I.D., Rossman, G.R., Wasserburg, G.J., 1994, Mantle-derived fluids in diamond micro-inclusions: Nature, 335, p. 784-789.

Schrauder, M., Koeberl, C., Navon, O., 1996, Trace element analyses of fluid-bearing diamonds from Jwaneng, Botswana: Geochim. Cosmochim. Acta, 61, p. 4711-4724.

Sunagawa, I., Tsukamoto, K., Yasuda, T., 1984, In: Materials Science of the Earth's Interior, Ed. Sunagawa, I., p. 303-331, Terrapub.

Yamaoka, S., Akaishi, M., Kanda, H., Osawa, T., 1992, Crystal growth of diamond in the system of carbon and water under very high pressure and temperature: J. of Cryst. Growth, 125, p. 375-377.

Zakharchenko, O.D., Khar'kiv, A.D., Botova, M.M., Makhin, A.I., Pavlenko, T.A., 1991, Inclusions of deep-seated minerals in diamonds from kimberlite rocks of the Northern part of East-European platform: Mineral. Journ., 13, p. 42-52. (in Russian)

Zezin, R.B., Ivanovskaya, I.N., Rodin, N.I., Galimov, E.M., 1981, Albstr. $1^{\text {st }}$ Natnl. Conf. Carbon Geochem., GEOKHI, p. 228-230. (in Russian) 